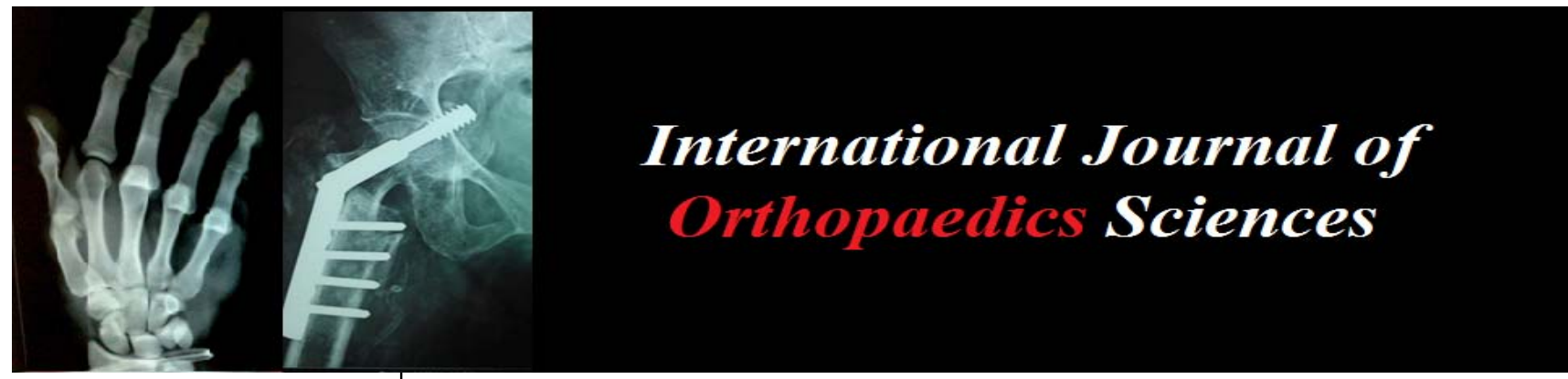

ISSN: $2395-1958$

IJOS 2017; 3(1): 308-313

(C) 2017 IJOS

www.orthopaper.com

Received: 19-11-2016

Accepted: 20-12-2016

Dr. Parth Gawatre

Senior Resident,

Department of Orthopaedics,

Government Medical College and

Hospital, Akola, Maharashtra,

India

Dr. Niravkumar Moradiya

Senior Resident,

Department of Orthopaedics,

GMERS Medical College

and General

Hospital, Gotri, Vadodara,

Gujarat, India

Dr. Kalpesh Patel

Junior Consultant, Arthroplasty

Department, Zydus Hospital,

Ahmedabad, Gujarat, India

Dr. Tarun V Desai

Assistant Professor,

Department of Orthopaedics,

GMERS Medical College

and General

Hospital, Gotri, Vadodara,

Gujarat, India

\section{Proximal and distal metaphyseo-diaphyseal fractures of tibia in adults treated with tibia interlock nail with multiaxial locking (A Study of 30 Cases)}

\author{
Dr. Parth Gawatre, Dr. Niravkumar Moradiya, Dr. Kalpesh Patel and \\ Dr. Tarun V Desai
}

DOI: $\underline{\text { http://dx.doi.org/10.22271/ortho.2017.v3.i1e.49 }}$

\section{Abstract}

Introduction: In recent years, closed reduction and minimally invasive plating and multidirectional locked intramedullary nailing have both become widely used treatment modalities for proximal and distal tibial metaphyseal fractures. This study was performed to evaluate the functional outcome of proximal and distal metaphyseo-diaphyseal fractures of tibia in adults treated with tibia interlock nail with multiaxial locking.

Materials and Methods: This randomized prospective clinical study was conducted on 30 adult patients with proximal and distal metaphyseo-diaphyseal fractures of tibia in adults at a tertiary trauma centre.

Results: We had achieved excellent results in $24(80 \%)$ of patients, good results in $5(16.66 \%)$ of patients and satisfactory result in 1 patient $(3 \%)$.

Conclusions: From this study, it is our interpretation that multiaxial locked intra-medullary nail is a good option in treatment of both closed and minimally open fractures of proximal and distal metaphyseodiaphyseal fractures of tibia.

Keywords: Humeral shaft fractures, flexible nails, closed reduction and internal fixation

\section{Introduction}

Among all the open fractures in the body, Tibia is the single largest bone that is commonly involved in open injury. Owing to the increase in vehicular accidents and industrial mishaps, high velocity trauma produces tibial shaft fractures in increasing numbers. By its location and by being subcutaneous in most of its length tibial shaft fractures tend to be open very commonly. Due to its precarious blood supply and scanty soft tissue coverage, Orthopaedic surgeons around the world have been fighting infections and union problems.

Intramedullary nailing of tibial fractures has been an effective modality which allows early ambulation and weight bearing and decreased dependency. The infection rate is also low as nailing is done as a closed procedure. Interlocking nail has provided excellent stability against axial shear and rotation forces and complex comminuted, open and closed tibial shaft fractures.

The concept of interlock nailing was given by Modney, which was subsequently modified and applied by Kuntscher by introducing "Detensor" nail. Klemn and Schellman introduced first interlock nail for tibia, which was modified by Kempf and Grosse. These pioneers developed the technique and implants which formed the basis of several designs and techniques available today.

\section{Aims and Objectives}

The aim of this study was to study the result of multi axial interlock nailing in all types of juxtaarticular fractures of tibia in terms of union, ankle and knee movement, infection and functional ability of the patient and compare the results as described in literature.

\section{Materials and Methods}

This was a prospective study of 30 Closed and open metaphyseal-diaphyseal fractures of tibia
Dr. Parth Gawatre

Senior Resident,

Department of Orthopaedics,

Government Medical College and

Hospital, Akola, Maharashtra,

India 
in 30 patients. All patients who were operated in our institute between-July 2014 to November 2015 were included.

\subsection{Inclusion criteria}

- Adult patients above 18 years of age

- Fractures at the level of Proximal-third and distal-third of Tibia

- Patients with closed and Gustilo-Anderson type I and Type II compound Tibial fractures

\subsection{Exclusion criteria}

- Patients aged less than 18 years

- Patients medically unfit for surgery

- Gustilo-Anderson Type III Compound fractures

- Fractures with intra-articular extension

3.3 Initial Management: The patient was examined thoroughly for vital signs, head injury, thoracoabdominal injury and other associated injuries. The distal circulation was checked and was examined for any neurological deficit. All wounds were covered by sterile dressing after cleansing and normal saline wash. Full length roentgenogram in anteroposterior and lateral views was taken of affected leg. Temporary immobilization was given by above knee posterior plaster splint. Patient was admitted and Skin ankle traction or calcaneal pin traction was given in all cases under anaesthesia and primary debridement was performed in open fractures. Tetanus prophylaxis in form of Tetanus Toxoid and Tetanus immunoglobulin were given. Parenteral antibiotics and analgesics were started. All limbs were kept elevated on Bohler-Braun splint in ward till patient got fitness for surgery.

3.4 Pre-operative measures: Cardiopulmonary and general condition of patient was assessed by physician if patient was of 35 years of age and above. Routine blood investigations chest roentgenogram and electrocardiogram were performed. Local parts were shaved and prepared with antiseptic solution and slabs were reapplied. Appropriate wound management was instituted for open trauma wounds. Preliminary Nail length was measured from tibial tuberosity to tip medial malleolus subtracting $2 \mathrm{~cm}$ clinically. Nail diameter was measured at level of isthmus in anteroposterior and lateral view.

3.5 Selection of Nail: We used Titanium or stainless steel (316L) AO type nail. Proximal end was having $15^{\circ}$ of bend at its upper end. Upper, out of the 5, 2 holes were in mediolateral direction, 2 Oblique and 1 anteroposterior. Of 4 lower holes 1 was in anteroposterior, 2 in mediolateral direction \& 2 is Oblique direction. Tip of nail was smoothly rounded to prevent inadvertent splintering of posterior cortex. Titanium or Stainless steel $4.9 \mathrm{~mm}$ or $3.9 \mathrm{~mm}$ cortical screws were used to lock the nail depending upon the sized of nail \& type of metal used.

3.6 Anaesthesia: All patients were operated under Spinal or Epidural anaesthesia.

3.7 Operative Technique: In all the patients closed nailing was carried out and if required secondary procedures on open trauma wound were done at the same sitting.

3.8 Position: Patient was kept supine on regular radiolucent operating table. The affected limb was scrubbed and prepared with antiseptic solution. Painting and draping was done under aseptic and antiseptic conditions. Draping was done in such a way that knee, ankle and foot remain exposed for manipulation.

3.9 Post-Operative Care: Immediately after surgery below knee slab was given and limb was elevated on Bohler splint. Patient was encouraged to do active toe movements and static quadriceps exercise. Analgesics were given for first 7 days and then if required. Antibiotics were given till original trauma wound heals. After suture removal either BK Slab was given and patient was discharged with either partial or non-weight bearing crutch walking depending on stability of fixation.

3.10 Follow up: Follow up was conducted regularly at the interval of 4 weeks till the union was achieved. At the time of follow up a thorough clinical and radiological evaluation was done for progress of union, healing trauma wound and acquired amount of joint stiffness. Once fracture had shown sign of union partial weight bearing on the injured limb was initiated. At the time of final follow up the patients were evaluated clinically, functionally and radiologically and results were graded as excellent, good, satisfactory(fair) and poor according to Dr. R.N. Daveshwar criteria

\section{Results}

We studied 30 patients having closed and open Metaphyseodiaphyseal tibia fractures; the primary aim in the treatment of tibial fractures was to produce clinical and radiological union with early mobilization having no functional disability or residual deformities.

In our study, patients were of age group between 18 to 65 years and maximum numbers of patients were in the age group of 21-30 years. Average age was $41.1 \mathrm{yrs}$. There was increased incidence in the younger people noted in our study. There were 26 males and 4 females in our study. There was definitive male preponderance. Occupation wise majority of the patients in our study were Labourer and farmers comprising $63.33 \%$. Labourer sustained maximum number of tibia fracture in our study. All females were Housewives. Vehicular accident was the dominant cause in our study to produce tibia injury in $66.66 \%$ of the total patients. Injuries caused due to domestic fall were the second most common mode of trauma, which was more common in the female population in our study.

All associated bony injuries were restricted to foot \& ankle, ipsilateral or contralateral. In our study $13.33 \%$ patients has other bony injury apart from the tibia fibula fractures. Both sides were almost equally involved this study (16 Right and 14 Left). None of our patients has bilateral injury. Most of the patients were operated within 6-10 days of injury. Average injury surgery interval was 6 days. Average hospitalization time was 11.56 days. Longer hospitalization was accounted for other associated injuries and due to bony fractures that required stabilization by operative means. Almost all patients were discharged after suture removal and adequate coverage of trauma wound or which showed satisfactory healing on discharge.

We had 19 closed fractures and 11 open fractures. The ratio of closed to open fractures was almost equal to $1.7: 1$. Of all the fractures almost 30\% were OG I and 6\% were OG II. Open Grade wounds were treated with primary suturing, local dressing and antibiotics and no further procedure was required. According to A-O classification, Type A accounted for $76.66 \%$ and Type B accounted for $10 \%$ of the total fractures and $\mathrm{C}$ accounted for $13 \%$. Distal metaphysical fractures of tibia in our study were $73.33 \%$. Maximum fractures were at 
distal third level which was 22 in our study. There were 8 higher upper third fractures seen in our study which, we could include for interlock nailing because of our unique nail design. 29 of our patients had associated fibula fracture commonest being distal third (18) followed by proximal third (11).

Most commonly used nail diameter was $9 \mathrm{~mm} \& 10 \mathrm{~mm}$. Average diameter in study was $9 \mathrm{~mm}$. All operated patients with rigid construct were discharged either with partial weight bearing crutch walking with $\mathrm{BK}$ slab or kept non weight bearing. They were made partial weight bearing on subsequent follow-ups as fracture progressed towards union clinically and radiologically. Average union time was 18 weeks which included all types of closed and open grade I and II fractures. $90 \%$ fractures showed union before 20 weeks. 2 of our cases had delayed union which subsequently united between 24-28 weeks and did not require any secondary procedure for union. Study showed that time increased for union as the grade of fractures increases. Highest time required was that in Grade II of around 20 weeks. 2 cases of delayed union were reported in our study. No non-union was seen in our study.

Three patients had anterior knee pain which interfered with routine activities of patients. 1 of our cases had superficial surgical site wound infection, for which patient was treated with daily dressing and IV antibiotics for 2 weeks following which the infection subsided without any sequelae. There were 3 cases of primary mal alignment which were close to acceptable criteria of fracture alignment and it did not interfere with daily activities of the patients. 1 of the 2 cases of delayed union had screw breakage which required removal. No nonunion was seen in our study.

On final assessment 7 patients were having union in a position deviating from anatomical alignment but close to our acceptable range of fracture alignment. All X-rays were assessed independently and 3 patients had valgus alignment while 4 patients had posterior angulation alignment. In our study only $10 \%$ patients has $<15^{\circ}$ restriction of knee ROM rest has full ROM. 90\% patients have no restriction in ankle ROM while rest showed only mild restriction. None of our patients had Shortening in our study. 27 out of 30 patients were able to squat with ease while rest were able to squat with difficulty. 27 patients were able to sit cross-legged with ease or minimal difficulty. There were $96 \%$ of excellent to good results in our studies and 3\% satisfactory results. There was not a single case with poor result in our study [Table 1].

Table 1

\begin{tabular}{|c|c|c|}
\hline Results & Patients & Percentage (\%) \\
\hline Excellent & 24 & 80 \\
\hline Good & 5 & 16.66 \\
\hline Satisfactory & 1 & 3 \\
\hline Poor & 0 & 0 \\
\hline Total & 30 & 100 \\
\hline
\end{tabular}

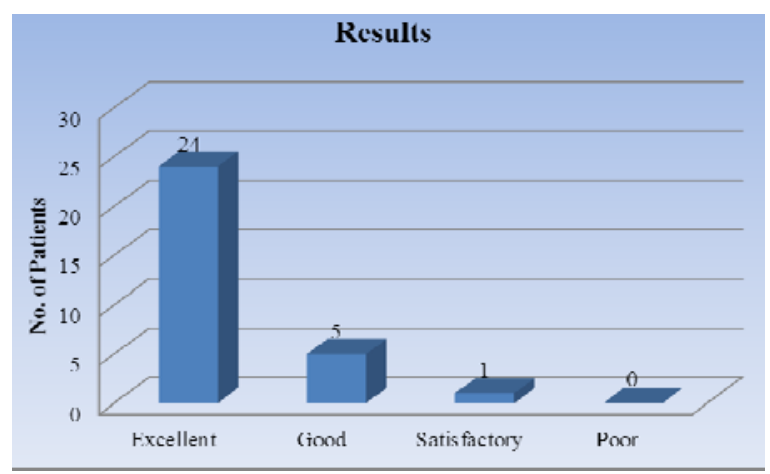

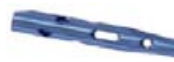

Multiaxial locking tibia Interlock nail
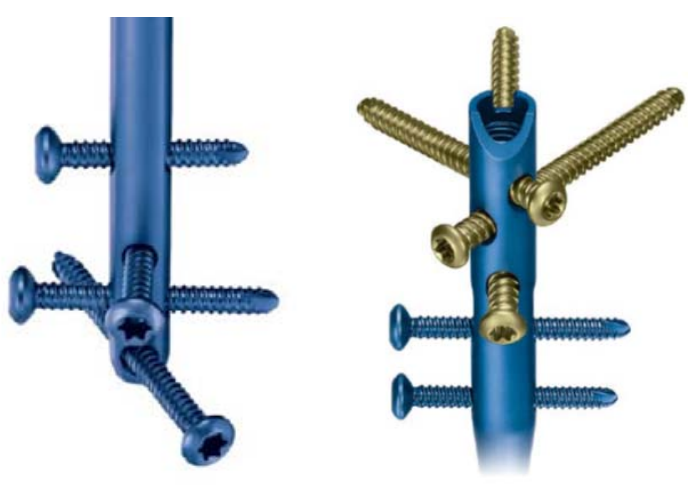

Proximal Locking

Distal Locking

Fig 1

\section{Discussion}

In the modern age due to high velocity trauma by vehicular accidents and industrial mishaps; tibial fractures are the most common long bone injuries. Stabilization of fractures by external fixator proved to be cumbersome, and high percentage of complications associated with casting and compression plating has led to increase in popularity of intramedullary nailing in tibia. Risk of infection and chances of non-union are higher in open tibial fractures due to its energy absorption in high velocity trauma, its subcutaneous location, its precarious blood supply and poor soft tissue coverage on one third of its circumference. To overcome problems, associated with casting and compression plating and external fixator and to solve the conflict, a delicate balance is needed to nail tibial fractures between presentation of fractures, and, the functional outcome of the treatment.

Conventional intramedullary nailing gave poor fixation in upper and lower end of the bone to overcome this problem a nail was developed that allows Interlocking screws to be inserted through the nail and the bone above and below the fracture site. The introduction of interlocking principle has extended the indications for intramedullary nailing and the device has proven to be an effective tool in treatment of many comminuted fractures. Interlock nail in open tibia was first used by Bone and Johnson in 1982 and they published their reports in 1986. Previously used intramedullary nail like Vnail and K-nail were not able to stand the test of time and failed in producing good results in high velocity tibial fractures.

Static nailing with introduction of screws above and below the fracture site, secures the best stability of the fracture. Dynamic nailing with interlocking screws only through one of the ends may be used for proximal or distal fractures. This allows the fracture site to be compressed during early weight bearing, which is thought to enhance fracture healing.

Wide availability of intramedullary nails has tremendously extended the application of nail in treatment of high velocity tibial fractures. Today with better understanding of biological effect of reaming and improvement in nail design and refinement in operative techniques the locked, intramedullary nail has become the treatment of choice for many complicated, unstable, open fracture of tibia.

During the use of conventional interlock nail with Herzog's bend at the junction of upper and middle third and proximal 
locking holes not near the upper end, we realized that we could not nail upper third and lower fourth fractures effectively. Even when such nails were used, it required prolonged immobilization with resultant complications and high failure rates.

How this study differed from previous studies on interlock nailing done in our institute on aspect of the type of nail used, which greatly expanded the indications of an interlock nail. Because of Fifteen degree Herzog's bend within $6 \mathrm{~cm}$ from the proximal end having 2 mediolateral, 2 oblique \& 1 anteroposterior proximal locking holes above the bend, and 4 distal locking holes with 3 plane locking gave us more flexibility to expand the indications to use the nail in almost all varieties of tibial fractures. At the same time, because of having 4 distal holes (1 anteroposterior, 2 mediolateral \& 1 oblique) within last $5 \mathrm{~cm}$ of nail, it was possible to nail even lower fourth fractures [figure 1]. Because of the versatility of this nail; we had an opportunity to include almost all varieties of tibial fractures ranging from upper third and lower fourths.

\subsection{The present study}

The present study consists of 30 patients having 30 tibial fractures treated by AO type intramedullary interlock nailing from July 2014 to November 2015. We compared the data, analysis and result in our study with the study done by CM. Court Brown who treated 125 open and closed tibial fractures with or without reaming between August 1985 and November 1987 and with Arne Ekeland who treated 45 tibial shaft fractures by interlock intramedullary nailing and presented his study in 1982 and with Bonatus who treated 72 tibial fractures with Unreamed interlock intramedullary nailing and presented his study in 1997.

5.2 Age: We had patients of age ranging between $18 \mathrm{yrs}$ and 65 yrs. Majority of patients were in 21 to 30 years of age group (40\%). Average age in our study was 41.1 years. We had good to excellent results in all patients younger than 50 yrs. Of 8 patients above 50 years all had good to excellent results.

Age distribution in CM. Court Brown study was 16 to 80 years with average of 32.4 years. Age distributed in Arne Ekeland study was 17-80 years with median age of 35 yrs. Age distribution in Bonatus study was 16 to 75 years with average of 30.7 years.

5.3 Sex: We have had 26 males $(86.66 \%)$ and 4 females $(13.33 \%)$ patients. Male female ratio is 6:1 Preponderance of male can be because of Males are more engaged in outdoor activities hence more vulnerable to vehicular accident. And Due to social customs, certain tasks which involve more risk are done by males e.g. working at heights, driving, and heavy labour and travelling.

CM. Court Brown had 100 male and 23 female patients Bonatus study had 52 male and 20 female patients. Arne Ekeland had 28 male and 15 female patients.

5.4 Occupation: We have had 12 patients as labourers $(40 \%)$, 4 as house wives $(13.33 \%), 7$ patients as farmers $(23.33 \%) 4$ Industrial workers (13.33\%) and 3 as other (10\%). Distribution of work pattern was somewhat similar to that of CM. Court Brown and Bonatu's study.

5.5 Mode of Injury: 20 patients $(66.66 \%)$ in our study had vehicular accident, 7 (23.33\%) had domestic fall, 2 patient had fall from height $(6 \%)$ while 1 patient was injured due to assault
$(3 \%) .(85 \%)$ of patients of vehicular accidents (17 out of 20$)$ excellent result, where as $50 \%$ of patients with domestic fall had excellent result and $100 \%$ excellent results were obtained in patients with fall from height. All patients with assault had excellent result. Thus, low velocity trauma had better results than high velocity.

CM. Court Brown study was having 39 patients who were involved in motor vehicular accident out of 125 patients, 35 were having fall from height, 45 were having sports injury and 6 were having industrial accidents, and in Arne Ekeland 23 fractures were caused by road-traffic accidents and other by fall and sports injuries.

5.6 Side Involved: We were having $16(53.33 \%)$ of patients having right sided fracture and 14 (46.66\%) were having left sided fracture. Therefore in our study there was no particular preponderance of laterality. We had no bilateral involvement. CM. Court Brown and Anne Ekeland each had 2 patients with bilateral involvement.

5.7 Type of Fracture (open and closed): We treated 19 $(63.33 \%)$ closed and $11(36.66 \%)$ open fractures. Of these we had 9 Type I (30\%) and 2 Type II (6\%). Grade of injury was decided according to Gustilo-Anderson's classification.

CM. Court Brown study had 9 Type I, Arne Ekeland series had 40 closed fractures and 5 open of the later, 3 were Type I and 2 were Type II. Bonatus study had 27 type I, 22 type II, 11 type III A and 12 type III B fractures.

5.8 Level of Fractures: We were having 8 (26.66\%) proximal metaphyseal and $22(73.33 \%)$ distal metaphyseal fractures. $3 / 4^{\text {th }}$ of the patients in our study comprised of distal metaphyseal fractures of tibia. Maximum fractures were at $\mathrm{L} / 3$ junction which was 22 in our study. There were 8 higher upper third fractures seen in our study which we could include for interlock nailing because of our unique nail design.

We have nailed every level of fractures that falls within the limit of intramedullary nailing.

CM. Court Brown study had $6 \mathrm{U} / 3,46 \mathrm{M} / 3$, and $64 \mathrm{~L} / 3$ and 9 segmental fractures. In AE study most were transverse or short oblique, $20 \%$ were comminuted and $11 \%$ segmental.

Bonatus study had $9 \mathrm{U} / 3,38 \mathrm{M} / 3$ and 25 distal third fractures. Our study is comparable to that of both the study.

5.9 Injury Operation Interval: We had nailed $10(33.33 \%)$ fractures within $<5$ days of trauma, $20(66.66 \%)$ fractures in 10 days of trauma. Delay in last group was due to unstable patient condition, associated injuries and due to their fitness problems. Early nailing has produced rapid soft tissue healing in our study.

In CM. Court Brown study injury operation interval was ranging from 4 hours to 5 weeks with an average of 78 hours.

In Arne Ekeland study 35 patients were operated upon within 3 weeks.

Bonatus had stabilized all fractures acutely with nail at the time of initial debridement.

5.10 Hospital period: We had average hospitalization period of 11.56 days ranging from $1 \mathrm{wk}$ to $3 \mathrm{wks}$. Longer stay was due to associated procedure for associated injuries. We had discharged patients only after their wound had shown satisfactory healing.

In Bonatus average hospitalization stay was 7 days. Average hospitalization stay in CM. Court Brown study was 7.1 days (range 2 to 42 days). 
5.11 Diameter of nail: We had used $8 \mathrm{~mm}, 9 \mathrm{~mm}, 10 \mathrm{~mm}$ and $11 \mathrm{~mm}$ diameter of nails. Average diameter in our study was $9 \mathrm{~mm}$. Most commonly used were $9 \mathrm{~mm}$ and $10 \mathrm{~mm}$ nail diameter. Because of small diameter of medullary canal in Indian patients, especially in females we were able to pass only $8 \mathrm{~mm}$ nail.

In Arne Ekeland study, medullary canal was reamed to a diameter at $12-14 \mathrm{~mm}$. Bonatus study was having average diameter of $9.1 \mathrm{~mm}$ ranging from 8 to $10 \mathrm{~mm}$.

5.12 Treatment of open wound: All open grade I and few open grade II wounds healed by local dressing and antibiotics. Other grade II injuries (6\%) healed by primary closure and local sterile dressing.

5.13 Mobilization protocol on discharge: We had discharged 25 of our patients with non-weight bearing crutch walking which eventually progressed to partial weight bearing crutch walking after 2 weeks and 5 patients with partial weight bearing crutch walking.

In Arne Ekeland study, Patient with static interlocking was encouraged to put partial weight on injured limb from $2^{\text {nd }}$ postoperative day.

Bonatus has advised 50\% weight bearing in all his stable statically locked patients. Gait training and full weight bearing was started within 2 to 4 weeks.

5.14 Fracture Union: Fracture was clinically assumed to be united when there was no tenderness at fracture site on palpation and full weight bearing and radiologically adequate callus was visible at fracture site with bridging of three of four cortices.

27 patients (90\%) showed early union before 20 weeks, 1 patient (3\%) showed union between 20-24 weeks while only 2 patients $(6 \%)$ had not united sufficiently even after 24 weeks however the patients showed union subsequently at 24 to 28 weeks. Average union time was 18 weeks. We achieved somewhat early union than other study.

CM. Court Brown study had average union time of 20.8 weeks ranging from 13 weeks to 70 weeks. Due to short follow up and small number of patients we had achieved early average time than other study. Arne Ekleland has 29 excellent, 13 good, 2 fair, and 1 poor result. Average union time was 16 weeks (range 8-40 wks) excluding one non-union.

In Bonatus study 49 patients (68\%) showed union within 24 weeks, 11 patients $(15 \%)$ showed union beyond 24 weeks and 12 patients $(17 \%)$ showed non-union.

In our study no case of non-union was recorded.

5.15 Complications: We had no cases of chronic osteomyelitis and 1 case of screw breakage. We had no case of non-union. We did not require any secondary bony procedure to heal the fractures. There were 7 patients with primary malalignment on X-rays which was within acceptable range. And none of our patients has any significant shortening. All deformities were within the acceptable range and no patient was functionally disabled. The anterior recess at the proximal end of the nail prevents irritation of patellar tendon after final nail position. Due to this we did not have any case of implant extraction. Inspite of that we had 3 case of anterior knee pain which interfered with the daily activities of the patients.

In CM. Court Brown study following complications was noted:

- Hypertrophic non-union -2 cases
- Deep infections - 2 cases

- Proximal tibial comminution during nail insertion - 4 cases

- Shortening of $2 \mathrm{~cm}$ in 1 and ext rotational deformity - 3 cases

- Compartment syndrome requiring fasciotomy - 2 cases

- Dysasthesia following sural nerve damage due to insertion of distal locking screw in 3 patients.

51 of the patients complained of knee pain of these 33 had the nail removed. Arne Ekeland had following complications:

- Infection in 2 cases

- Rotational malalignment in 2 patients.

- Non-union in 1 case

35 patients had their nail extracted.

In Bonatus study there was 5 malunion, 1 breakage of screw, 3 chronic osteomyelitis and 12 non-union cases, which required secondary procedure like bone grafting and dynamization.

5.16 Knee range of movements: Looking at the lifestyles and working patterns of Indian patients we have given much importance to knee and ankle range of movement which is necessary for patients to sit and squat.

The possible causes for restriction of knee movement range from associated trauma at the time of injury, associated degenerative disease of knee joint like osteoarthritis, to irritation of patellar tendon by the nail, scaring of quadriceps due to the prolonged immobilization in cast and lack of patients compliance to physiotherapy.

We had all patients, having up to $135^{\circ}$ of knee flexion required for their daily routine activities. In our study only 3 patients $(10 \%)$ has $<15^{\circ}$ restriction of knee range of motion while other had near full range of motion.

In CM. Court Brown study $92.8 \%$ of patients had full range of knee movements at one year.

5.17 Ankle range of movements: Ankle range of motion is also as important as knee movement specially for Indian patients who need to squat during their daily activities. Possible causes for restriction of ankle movement include associated trauma at the time of injury, tethering of tendons to fracture site in distal and open grade fractures, prolonged cast immobilization, and lack of patients' compliance towards physiotherapy.

27 patients $(90 \%)$ had no restriction of ankle movement while only 3 patients $(10 \%)$ had $<10^{\circ}$ of ankle range of motion restriction.

In CM. Court Brown study 7 patients had lost $5-10 \%$ of movement at the ankle.

5.18 Limb Length Discrepancy: Possible causes of shortening include bone loss at the time of trauma, collapse of fracture site due to dynamically locking or dynamization especially in comminuted cases.

None of our patients had any significant shortening.

5.19 Squatting and sitting cross-legged: We have included these criteria in our study looking at the life style and daily activities of Indian patients. Other study has not made a mention of these criteria.

On final follow up 27 patients $(90 \%)$ were able to squat and sit cross-legged with ease, 3 patients $(10 \%)$ had difficulty in squatting. 3 patients $(10 \%)$ had difficulty in sitting crosslegged due to restriction of knee movements. 
We have emphasized much on squatting and sitting crosslegged, as it is required in our daily activities of Indian patients. Good to excellent results were achieved in $100 \%$ of patients. Despite minimal difficulty no patient had any functional disability.

5.20 Condition of trauma wound: On our final follow up assessment, all were having healed trauma wound. All patients were satisfied with their limb condition and appearance.

5.21 Results: Considering the radiological union, Radiological deformities, malunion, knee, ankle and foot range of movements, infections, shortening and patients satisfaction, we had achieved excellent results in $24(80 \%)$ of patients, good results in $5(16.66 \%)$ of patients and satisfactory result in 1 patient $(3 \%)$. All patients returned to their pre trauma work and none had changed his/her occupation.

\section{Conclusion}

We concluded that primary intramedullary nailing is safe and effective treatment of choice for proximal as well as distal Metaphyseo-diaphyseal fractures of tibia, giving consistently excellent and good results.

\section{References}

1. Nork SE, Barei DP, Schildhauer TA et al. Intramedullary nailing of proximal quarter fractures, J Orthop Trauma. 2006; 20(8):523-528.

2. Trlica J, Dedek T, Smejkal K, Kocí J, Lochman P, Frank M. Expert Tibial Nail (ETN) for treatment of diaphyseal tibial fractures in current and extended indications: technique and clinical results. Acta Chir Orthop Traumatol Cech. 2010; 77(3):235-41.

3. Attal R, Müller M, Hansen M, Bail H, Kirjavainen M, Hammer $\mathrm{T}$ et al. Rommens Treatment of tibia fractures with the expert tibia nail. Journal of Bone and Joint Surgery - British 91-B(Issue SUPP-I): 10

4. Kuhn S, Hansen M, Rommens PM. Extending the indications of intramedullary nailing with the Expert Tibial Nail Acta Chir Orthop Traumatol Cech. 2008; 75(2):77-87.

5. Hansen M, El Attal R, Blum J, Blauth M, Rommens PM. Intramedullary nailing of the tibia with the expert tibia nail. Oper Orthop Traumatol. 2009; 21(6):620-35.

6. Nork SE, Schwartz AK, Agel J et al. Intramedullary nailing of distal metaphyseal tibial fractures. J Bone Joint Surg Am. 2005; 87(6):1213-1221.

7. John Gorczyca T, McKale James, Pugh Kevin, Pienkowski David. Modified Tibial Nails for Treating Distal Tibia Fractures. Journal of Orthopaedic Trauma. 2002; 16(1):18-22.

8. A Darder Gracia. A Darder Parts, Nonreamed Flexible locked intramedullary nailing in tibial open fragctures; Clinical Orthopaedics. 1998, 350-104.

9. Arne Ekeland, Bjorn OT. Interlocking intramedullary nailing in the treatment of tibial fractures; Clinical. 1988; 231:205-215.

10. Antti Alho, Knut Stromose. Locked intramedullary nailing for displaced tibial shaft fracture. JBJS. 1990; 72(B):805809.

11. Chaurasia's BD. human anatomy; Regional and applied 1llrd edition CBS publishers and distributers. 1998.

12. Bone LB, Kenneth DJ. Treatment of tibial fractures by reaming and intramedullary nailing. 1986; 68(A):887.

13. Boyton MD, Schwelling GJ. Intramedullary nailing in open tibial fractures; Journal of American Ortho society. 1994; 2:107-116.

14. Campbell WC. Operative orthopaedics; $9^{\text {th }}$ edition; Mosby.

15. Court Brown CM, Mo Queen MM. Locked intramedullary nailing of open tibial fractures; JBJS. 1991; I73(B):959964.

16. Christian Krettek. Peter Schandelmaier; Nonreamed Interlocking nailing of closed tibial fractures with severe soft tissue injuries; Clinical Orthopaedics. 1995; 315:3447.

17. Eric Feedman L, EricE Johnson. Radiographic analysis of tibial fractures Malalignment following intramedullary nailing; Clinical Orthopaedics. 1995; 315:25-33.

18. Grant's Atlas of anatomy; $9^{\text {th }}$ edition Wilkins.

19. Gracia Lopez, Marko F, Duran L. Unreamed intramedullary locked nailing for open tibial fractures; Int Ortho. 1998; 22(2):97-101.

20. Gain CM Francescos. Intramedullary nailing in Segmental Tibial fractures; JBJS. 1981; 63CA:1310-1318.

21. Gustilo RB. Anderson JT. Prevention of infection in the treatment of one thousand and twenty five open fractures of long bones; JBJS. 1976; 58(A):453-489.

22. Dean Cole J, Loeri J, Ansel A. sequential protocal for management of severe open tibial fractures; Clinical Orthopaedics. 1995; 315:84-103.

23. Paul Harvey J Jr. Management of open tibial fractures; Clinical Orthopaedics. 1974; 105:154-165.

24. Keating JF, O' Brien PJ, Blachut PA, locking intramedullary nailing with and without reaming for open fractures of tibial shaft; JBJS. 1997; 79(3):334-341.

25. Keating JFO', Brien PJ. Reamed Intramedullary nailing of open tibia fractures; Clinical Orthopaedics. 1997; 338:182-191.

26. Hamza KN, Dunkerley GE. Treatment of tibial fractures by intramedullary nailing JBJS. 1971: 53(B):696-700.

27. Konnstaining PV. Primary internal fixation in open fractures of the tibial shaft, JBJS. 1959; 41(B):342-355. 